\title{
Warning symptoms before major myocardial infarction
}

\author{
Mary Stowers and David Short \\ From The Royal Infirmary and Woodend General Hospital, Aberdeen
}

One hundred and eighty patients in hospital with proven myocardial infarction were questioned during their recovery about any unusual symptoms they experienced during the two months before the diagnosis of infarction.

One hundred and twenty-two (68\%) admitted to such symptoms. Ninety-nine (55\% of the total) said they had experienced either the onset or an intensification of attacks of pain in the chest. Twenty-three (13\%) described other symptoms, particularly tiredness or breathlessness.

Of the I22 patients with prodromal symptoms, only 36 consulted their doctors, and of these I4 received only reassurance.

The fact that such a high proportion of patients experience prodromal symptoms gives ground for hope that myocardial infarction might be averted in many instances. To achieve this, doctors need to be better trained to recognize the early symptoms of coronary heart disease, and, above all, further research is urgently needed to establish an effective prophylactic regimen. Once these goals have been achieved, there will be a strong case for educating the public to recognize coronary symptoms.

Much attention is being focused at the present time on the early and intensive treatment of myocardial infarction, and rightly so. But since two-thirds of the deaths from coronary heart disease occur before the patient can be brought to hospital (Kuller, 1969), and since in any case prevention is better than cure, the anticipation and prevention of infarction is even more important.

It is well known that a proportion of patients who develop recognizable infarction have experienced specific symptoms days or weeks beforehand. In this study, an attempt has been made to discover the incidence and exact nature of such symptoms; and also the action taken by patients experiencing them, and the reaction of their doctors if consulted.

\section{Method}

Our information regarding prodromal symptoms was obtained primarily by interviewing patients in hospital recovering from acute infarction. The interview usually took place during the first two weeks after admission, at a time when the patient was past the acute phase and feeling comfortable, and yet sufficiently soon after the onset for the prodromal period to be fresh in mind. The interval between admission and interview was 7 days or less in 46 per cent of cases, 8 to 14 days in 36

Received 13 April 1970. per cent, and over 14 days in 18 per cent. The information obtained at this interview was checked and supplemented by reference to the case records. We decided to exclude patients over the age of 70 because a significant proportion of them would be likely to suffer from impairment of memory.

A standardized form was completed in respect of each patient. On this was noted the evidence for the diagnosis of infarction, and any complication which developed during the stay in hospital. The patient was asked specifically about any symptoms he experienced during the two months before admission, and particular note was made of any pain which had been felt at the site of origin or greatest intensity of the subsequent infarct pain, and which resembled it in character. The distribution of the pain (or discomfort) was recorded on a chart of the chest and arms. The patient was also asked whether he had consulted his doctor about his symptoms and whether he had rested either on medical advice or on his own initiative. The patient's occupation was also noted with a view to correlating this with the results of the survey, but it proved impracticable to classify this information in a satisfactory way.

In the first 54 cases studied, an attempt was made to interview a close relative of the patient in order to obtain corroborative or supplementary information about the prodromal symptoms. The result was disappointing. In 19 cases no relative could be interviewed. In the remaining 35 cases a relative was interviewed, but in only 14 
instances was additional information forthcoming, and even this was of a vague and indefinite nature. Thus, irritability had been noted in 7 cases, tiredness in 3, breathlessness in 3, and ankle swelling in I case. In view of the small proportion of patients about whom the additional information could be obtained, and the vague quality of the information, the interviewing of relatives was discontinued.

\section{Subjects}

One hundred and eighty patients with acute myocardial infarction were interviewed while in the Royal Infirmary or Woodend General Hospital, Aberdeen, between I October 1968 and 12 May 1969. There was not time to interview every patient with confirmed infarction during this period, but only those over the age of 70 were deliberately excluded. The age and sex distribution of the patients is shown in Table $\mathrm{I}$ and their previous cardiac status in Table 2.

TABLE I Age and sex of patients

\begin{tabular}{llllll}
\hline & \multicolumn{2}{l}{ Age $(y r)}$. & & & Total \\
\cline { 2 - 6 } Sex & $<40$ & $40-49$ & $50-59$ & $60-69$ & \\
\hline Male & 4 & 21 & 54 & 52 & 131 \\
Female & 0 & 4 & 20 & 25 & 49 \\
\hline Total & 4 & 25 & 74 & 77 & 180 \\
\hline
\end{tabular}

All the patients included in this study had a firm diagnosis of recent myocardial infarction on the basis of one or more of the criteria listed in Table 3. One hundred and forty-eight ( $82 \%)$ were regarded as having sustained serious infarction on the basis of one or more of the following signs: recent abnormal $Q$ waves, aspartate transaminase (SGOT) of over I5O units, the development of heart failure (manifested by dyspnoea, a rise of venous pressure to at least $5 \mathrm{~cm}$. above the sternal angle, or oedema), the presence of shock or a systolic blood pressure below I00 $\mathrm{mm}$. $\mathrm{Hg}$, a major dysrhythmia, or death.
TABLE 3 Criteria for diagnosis of acute infarction

I) Major ST segment elevation with classical evolution

2) Abnormal $Q$ waves, together with serial $S T$ and/or $T$ wave abnormalities or a classical history of recent infarction

3) Diagnostic serum enzyme pattern in association with electrocardiographic changes or cardiac pain at rest or both

4) Serial $S T$ and/or $T$ wave changes of coronary type associated with either cardiac pain at rest or effort angina of recent onset or crescendo type

5) Necropsy confirmation

\section{Results}

Of the 180 patients in this study, all with proven myocardial infarction, $122(68 \%)$ gave a history of unusual symptoms beginning during the two months before admission (Fig. $\mathrm{r}$ ). In $99(55 \%)$, the outstanding symptom was the onset or intensification of attacks of pain or discomfort at the site of origin or greatest intensity of the pain which subsequently led to their admission. In $23(13 \%)$, the dominant symptom was unexplained tiredness (12), breathlessness (7), intermittent claudication (2), palpitation (I) or oedema of the ankles.

Prodromal pain Most patients found it difficult to describe the character of the prodromal pain they experienced. Some regarded it as severe, but many described it as more of a discomfort than a pain. They were usually much more definite in their description of its situation. Almost half (44) described it as extending across the chest; usually at the midsternal level, sometimes above, and occasionally below this level. Rarely, the sensation was said to cover the whole of the front of the chest. Patients with pain spreading across the chest frequently gave a spontaneous demonstration of its situation by means of a gesture

TABLE 2 Cardiac status of patients before two-month prodromal period

\begin{tabular}{|c|c|c|c|c|c|c|c|c|c|}
\hline \multirow[t]{3}{*}{ Cardiac status } & \multicolumn{9}{|c|}{ Age and sex } \\
\hline & \multicolumn{2}{|l|}{$<50$} & \multicolumn{2}{|c|}{$50-59$} & \multicolumn{2}{|c|}{$60-69$} & \multicolumn{2}{|c|}{ All ages } & \multirow[b]{2}{*}{ Both sexes } \\
\hline & $M$ & $F$ & $M$ & $F$ & $M$ & $F$ & $M$ & $F$ & \\
\hline \multirow{3}{*}{$\begin{array}{l}\text { Recognized previous infarction } \\
\text { With persisting angina of effort } \\
\text { Without persisting angina of effort }\end{array}$} & & & & & & & & & \\
\hline & I & I & 8 & 4 & 6 & 4 & 15 & 9 & 24 \\
\hline & 3 & $\circ$ & 3 & $\mathbf{I}$ & 7 & 3 & 13 & 4 & 17 \\
\hline \multicolumn{10}{|l|}{ Angina of effort } \\
\hline Without recognized infarction & 2 & 2 & 16 & 6 & 14 & 4 & 32 & 12 & 44 \\
\hline No previous cardiac symptoms & 19 & $\mathbf{I}$ & 27 & 9 & 25 & 14 & 71 & 24 & 95 \\
\hline Total & 25 & 4 & 54 & 20 & 52 & 25 & 131 & 49 & 180 \\
\hline
\end{tabular}




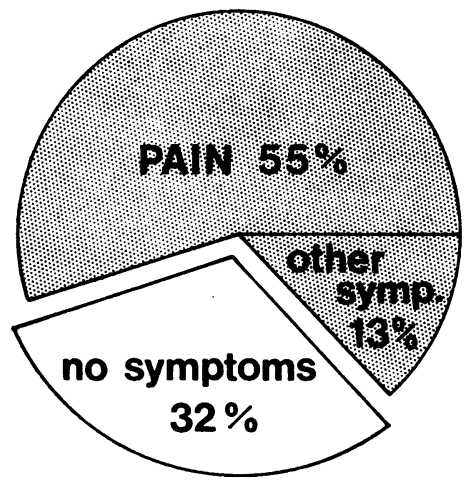

FIG. I Incidence of prodromal symptoms in the 180 cases studied.

in which the flat of the hand was passed to and fro across the chest at the appropriate level.

Almost one-third (29) of the patients described the prodromal pain as being localized in the mid-line; most commonly at the midpoint of the sternum, less commonly above or below this level. These patients frequently reinforced their description by a gesture in which the clenched fist was placed against the sternum at the level at which the pain was felt.

One-fifth (19) of the patients described the pain as situated in the left side of the chest, often extending to the mid-line, but not into the right chest. Seven patients located the pain in other sites; namely the neck (four cases), the right side of the chest, the left arm, or the left hypochondrium.

In nearly half the patients (43 out of 99) the prodromal pain occurred only on effort and was relieved by rest (Fig. 2). In many it had a crescendo course, becoming progressively more easily induced, more frequent, more severe, and more widespread, until it culmin-

FIG. 2 Relation of prodromal pain to effort.

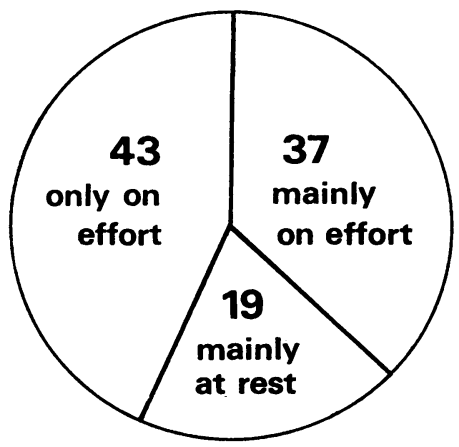

ated in the episode which necessitated admission to hospital. This was especially true of those who suffered from long-standing angina. In over one-third of the patients (37), the pain occurred mainly on effort, though sometimes at rest. In one-fifth (19), the attacks occurred mainly at rest; sometimes these attacks were brief, but in half the cases they lasted for over 30 minutes.

The interval between the onset of prodromal cardiac pain (or exacerbation of angina) and the occurrence of major infarction is shown in Fig. 3. In 6 cases warning symptoms appeared within 24 hours of major infarction, but in the majority, the interval was between $I$ and 8 weeks. The pattern of occurrence of prodromal pain once it appeared was very variable, especially in those patients in whom it occurred mainly at rest. Some of these had fairly long intervals of freedom between the first occurrence and the development of major infarction.

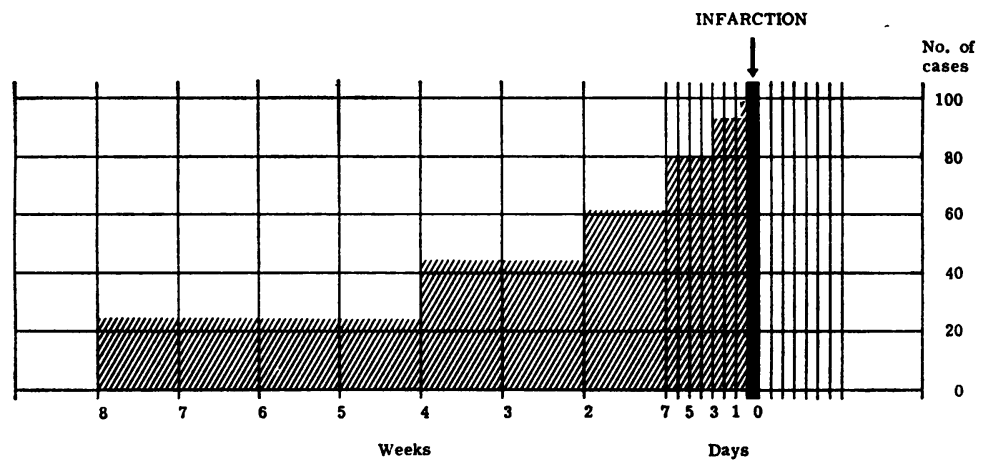

FIG. 3 Interval between onset of pain and infarction.

The incidence of prodromal symptoms was approximately the same in those patients with previous infarction and those without, and also in those with chronic angina pectoris and those without; nor was there any significant difference in relation to age or sex.

Action taken by patients with prodromal symptoms Thirty-five of the 99 patients with prodromal cardiac pain consulted their family doctors about their symptoms in the month preceding admission. Twenty-two said they were advised to rest, and did so. Six rested on their own initiative, and one because of the development of symptoms of carcinoma of the bronchus. Thus 29 of the 99 patients with prodromal chest pain or discomfort rested (Fig. 4). The degree of rest varied greatly: some stayed in bed; others merely cut out their heavier duties. One of the 23 patients 


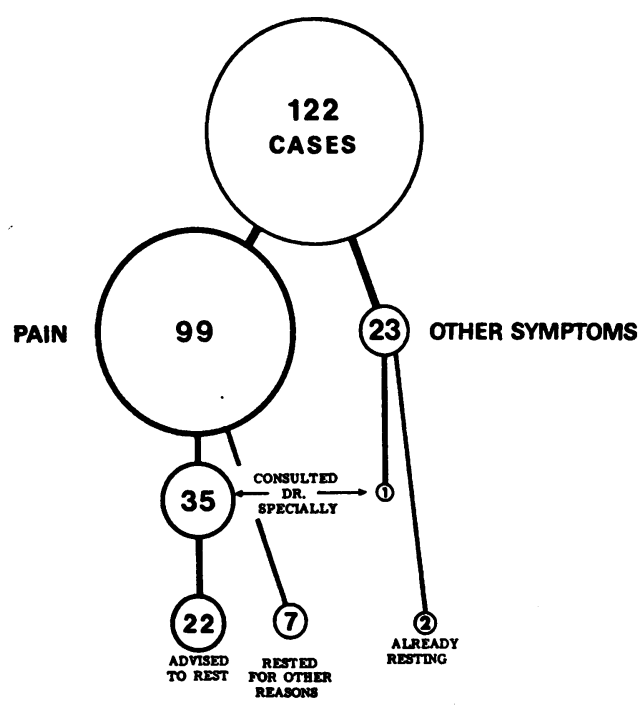

FIG. 4 Action taken by patients with prodromal symptoms.

with prodromal symptoms other than pain consulted his doctor, but he was not advised to rest. Two patients in this group were already resting on account of heart disease.

Relation between prodromal symptoms, rest, and severity of infarction This study was not designed to show whether the appearance of prodromal symptoms or the institution of rest had any bearing on the outcome, and it would be unwise to draw any such conclusions from it. So far as the evidence of this series goes, the proportion of patients with serious infarction was similar in the group who rested and the group who did not, and among those with prodromal symptoms and those without (Table 4).

TABLE 4 Relation between prodromal symptoms, rest, and severity of infarction

\begin{tabular}{lccccc}
\hline \multirow{2}{*}{$\begin{array}{l}\text { Prodromal } \\
\text { symptoms }\end{array}$} & $\begin{array}{l}\text { No. of } \\
\text { cases }\end{array}$ & \multicolumn{3}{l}{ Severity of infarction } \\
\cline { 3 - 6 } & & \multicolumn{2}{l}{ Serious } & \multicolumn{3}{c}{ Moderate } \\
\cline { 3 - 6 } & & No. & $\%$ & No. & $\%$ \\
\hline Present & 122 & 98 & 80 & 24 & 20 \\
Pain & 99 & 79 & 80 & 20 & 20 \\
Other & 23 & 19 & 83 & 4 & 17 \\
Absent & 58 & 50 & 86 & 8 & 14 \\
Rest & $37^{\star}$ & 30 & 81 & 7 & 19 \\
No rest & 143 & 118 & 83 & 25 & 17 \\
\hline
\end{tabular}

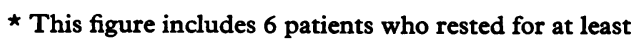
a week before infarction, not on account of prodromal symptoms but for other medical reasons.

\section{Discussion}

Though myocardial infarction is widely believed to strike without warning, this study shows that the majority of patients admitted to hospital on account of infarction are able to recall premonitory symptoms extending back for days and often weeks before admission.

Incidence of prodromal symptoms in myocardial infarction In our series of I80 patients interviewed in hospital during the recovery period, 68 per cent recalled symptoms that were probably of cardiac origin. In 55 per cent, the symptom was pain or discomfort similar in site and character to the more severe and widespread pain which led to their admission. In the remainder, the commonest prodromal symptoms were tiredness or breathlessness.

The incidence of prodromal pain which we report is higher than that reported by most previous workers, e.g. Master, Dack, and Jaffe (I94I), 27 per cent of 260 patients; Mounsey (195I), 29 per cent of 139; Vakil (1966), 36 per cent of 2992 ; and Wood (1961), 45 per cent of 100; but it agrees closely with the figure of 59 per cent of 100 patients found in the carefully designed study of Solomon, Edwards, and Killip (1969).

All the above figures refer to patients who survived myocardial infarction and could be questioned subsequently, but a considerable proportion of patients who experience acute infarction die before they reach hospital. How many of these have prodromal symptoms? There is little evidence on this point, but what there is suggests that the proportion is much the same. Kuller (1969) found that 23 per cent of patients who died suddenly from coronary heart disease in Baltimore had seen a physician during the previous week. This is very similar to the figure of 20 per cent in our series, and suggests that the incidence of prodromal symptoms is comparable.

Is there any action which can be taken to avert infarction? The fact that a considerable proportion of patients experience cardiac symptoms several days or even weeks before developing a major infarct means that there is time for preventive action in these cases. But is there any effective action which can be taken?

First, it should be made clear that the use of the term 'prodromal' should not be taken to imply that no infarction has as yet occurred. On the contrary, there is evidence to suggest that the onset of angina of effort, or cardiac pain at rest, frequently indicates the presence 
of a small infarct. Such symptoms may nevertheless be considered to be prodromal in the sense that they serve as a warning of a further, and perhaps more dangerous, infarct.

The question then is: can the progression to major infarction be averted? Theoretically, rest and anticoagulant therapy might be expected to be beneficial; but unfortunately there is no firm basis for this opinion. Experience shows that rest by itself is inadequate, particularly in the case of those patients whose attacks of cardiac pain come on at rest; and this view is supported by the present study. The main hope at the present time rests on anticoagulant therapy, but the evidence for its value is by no means conclusive. According to Mitchell (1969), the only completely acceptable study of the ability of anticoagulant therapy to prevent patients presenting with angina pectoris from subsequently developing myocardial infarction is that of Borchgrevink (1962). This worker divided 147 patients $(78 \%$ men) under the age of 70 years, who had suffered from angina pectoris for 4 weeks to 2 years, into 2 random groups. One group of 74 patients received intensive anticoagulant therapy. The other group of 73 patients received moderate anticoagulant therapy for 18 to 20 months, and then intensive therapy. The average period of observation was 3 years per patient. Only one of the 74 patients on continuous intensive therapy died compared with 13 of the 73 patients in the other group.

The best action at the present time seems to be to advise patients with recent symptoms of coronary origin or an exacerbation of previous symptoms to stop work, and rest at home without being confined to bed, until their symptoms have subsided completely; they should then undergo gradual rehabilitation. If cardiac pain occurs at rest, treatment with heparin and one of the oral anticoagulant drugs, such as warfarin, should be started at once. This advice can only be regarded as provisional. Further research is urgently needed to determine the most effective means of averting major infarction.

Recognition of prodromal coronary symptoms Assuming that preventive measures are worth while, or that effective therapy will become available in the future, what can be done to increase medical awareness of the significance of coronary symptoms ? It is disquieting to find that over one-third of the patients who consulted their doctors with prodromal cardiac pain received only reassurance. This undoubtedly reffects the difficulty of diagnosing coronary heart disease at an early stage - a difficulty that remains even when electrocardiography is freely available (Short, 1968). Indeed, this is one of the most onerous burdens placed upon the family doctor. If he reassures a patient with early symptoms of coronary disease, the result may be catastrophic; but if he fails to reassure an anxious patient with benign chest pain, the long-term effect may also be serious.

By far the most frequent and specific prodromal symptom is cardiac pain, and it is most important to recognize it. The first point to make is that it is not always described as a pain, but frequently as a pressure, a discomfort, a feeling of indigestion, or a sensation like wind trapped in the stomach. The second point to emphasize is that it is not always felt like a band across the chest, or localized to the sternum. In one-fifth of our patients, the pain or discomfort was felt to the left of the sternum, or in the neck, and rarely in other sites. The majority of the patients said the symptom was induced by exertion and relieved by rest. Such a description is virtually diagnostic of cardiac ischaemia, and patients with such a history must be regarded as having cardiac disease until proved otherwise. An important minority of patients, however (approximately one-fifth in this series), said that their pain or discomfort occurred mainly at rest. In these cases the demonstration which accompanied the description was often helpful: the passing of an open hand to and fro across the chest, or the pressing of a clenched fist against the sternum. Both these gestures are highly suggestive of cardiac pain.

\section{Should the public be educated to recog-} nize coronary symptoms ? Our study disclosed that nearly two-thirds of patients with prodromal symptoms failed to seek medical advice before the onset of major infarction. They were obviously unaware that their symptoms had any serious significance. There is therefore a strong prima facie case for educating the public in this field. Furthermore, it is certain that many intelligent men and women would welcome such advice, because the seriousness of coronary heart disease and the possibility of sudden death are now widely recognized. But any such programme of lay education would inevitably cause needless anxiety to many people with benign chest pain. Such a risk could only be contemplated if prophylactic treatment of proved value were available, and at the present time it is not. In the meantime we consider that lay education should take the form of general advice on healthy living, emphasizing such things as taking regular exercise, and the avoidance of obesity and smoking (Oliver and 
Stuart-Harris, I965); and this education should begin at school.

We wish to express our thanks to the consultant physicians and their staffs who so willingly provided us with the facilities for this study, and to the Board of Management of the Aberdeen General Hospitals for the provision of a research grant to M.S.

\section{References}

Borchgrevink, C. F. (1962). Long-term anticoagulant therapy in angina pectoris. A follow-up study. Lancet, $1,449$.

Kuller, L. (1969). Sudden death in arteriosclerotic heart disease. The case for preventive medicine. American fournal of Cardiology, 24, 617.

Master, A. M., Dack, S., and Jaffe, H. L. (194I). Premonitory symptoms of acute coronary occlu- sion; a study of 260 cases. Annals of Internal Medicine, I4, II55.

Mitchell, J. R. A. (1969). Anticoagulant therapy in ischaemic heart disease. Abstracts of World Medicine, 43, 249.

Mounsey, P. (I95I). Prodromal symptoms in myocardial infarction. British Heart fournal, 13, 215.

Oliver, M. F., and Stuart-Harris, C. H. (1965). Present position concerning prevention of heart disease. British Medical fournal, 2, 1203.

Short, D. (1968). Value and limitations of electrocardiogram in diagnosis of slight and subacute coronary attacks. British Medical fournal, 4, 673.

Solomon, H. A., Edwards, A. L., and Killip, T. (1969). Prodromata in acute myocardial infarction. Circulation, 40, 463.

Vakil, R. J. (1966). Diagnosis and management of the intermediate coronary syndrome: a clinical study of 400 cases of the syndrome. Fournal of the Association of Physicians of India, 14, 259.

Wood, P. (I96I). Acute and subacute coronary insufficiency. British Medical fournal, I, 1779. 